\title{
Regularity maintenance properties under deformation of kink-introduced Nano-mille-feuille structures derived from interfacial friction
}

Takato Ohashi, Nanata Kikuchi, and Atsuhiro Fujimori*

Graduate School of Science and Engineering, Saitama University, 255 Shimo-okubo, Sakura-

ku, Saitama 338-8570, Japan

*Corresponding Author

Tel and Fax: +81-48-858-3503

E-mail address: fujimori@apc.saitama-u.ac.jp

Keywords: Regularity Maintenance Property, Nano-mille-feuille, Nanokink introduction,

Deformation by Uniaxial Drawing, Interfacial Friction 


\section{[Figure Caption]}

Figure S1. (a) Surface pressure-area isotherm of polystyrene nanosphere on the water surface, and AFM image of its transferred monolayer on substrate (Upper illustration; the formation process of polystyrene nanosphere at the air/water interface. AFM images show the high-density region and the defect-containing region, respectively). (b) Surface pressure-area isotherm of organo-modified $\mathrm{Fe}_{3} \mathrm{O}_{4}$ on the water surface, and AFM image of its transferred monolayer on substrate (AFM images show the high-density region and the defect-containing region, respectively).

Figure S2. (a) and (b) Ouf-of-plane and in-plane XRD profiles of LB film of stearic acid used in this study, respectively $\left(25 \mathrm{mNm}^{-1}, 15^{\circ} \mathrm{C}\right)$.

Figure S3. Out-of-plane XRD profiles and paracrystal analysis of multi-particle layers of (a) organo-modified magnetite as the hard layer and (b) polystyrene nanosphere as the soft layer on resin substrate, respectively

Figure S4. Out-of-plane XRD profiles and paracrystal analysis of Nano-mille-feuilles on glass substrate.

Figure S5. XRD profiles of polypropylene resin substrate with drawing.

Figure S6. Dependence of the results of paracrystal analysis of the Nano-mille-feuille on the resin substrate due to changes in the draw ratio. 
Figure S7. Dependence of the results of paracrystal analysis of kink-introduced Nano-millefeuille on the resin substrate due to changes in the draw ratio.

Figure S8. Schematic diagram of interfacial friction and structural maintenance characteristics caused by the kink-introduced Nano-mille-feuille structure in this study (presented as a moving image in a separate file).

Figure S9. Repeated evaluation of order maintenance characteristics of Nano-mille-feuille by out-of-plane XRD (drawing-tension release-shrinkage-re-drawing process). 
(a)

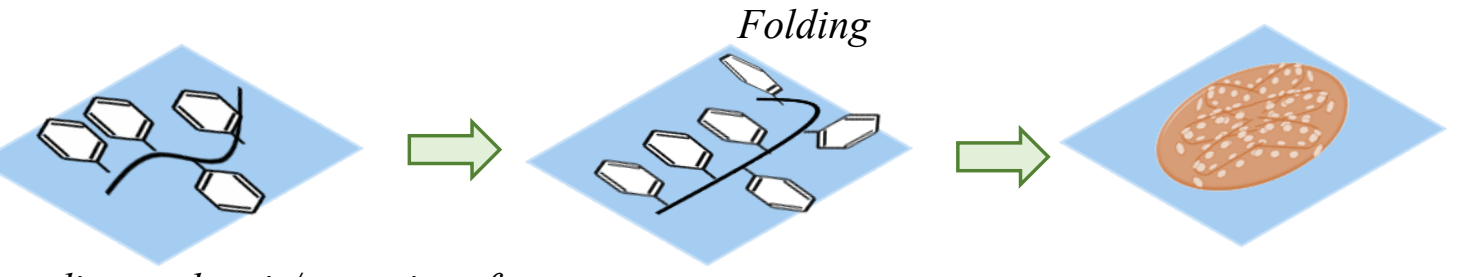

Spreading at the air/water interface
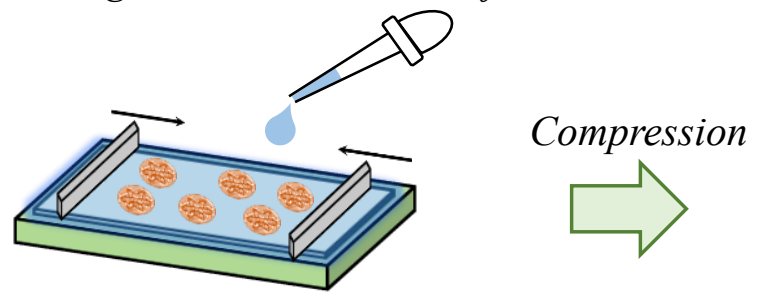

Formation of single particle

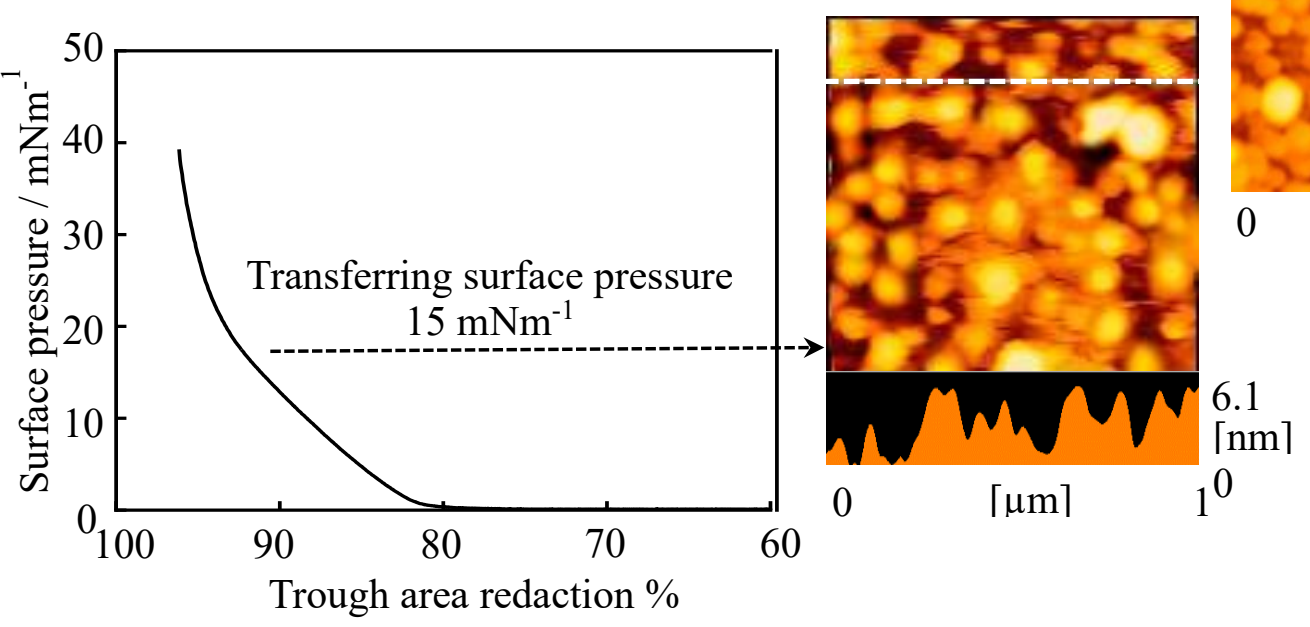

(b)
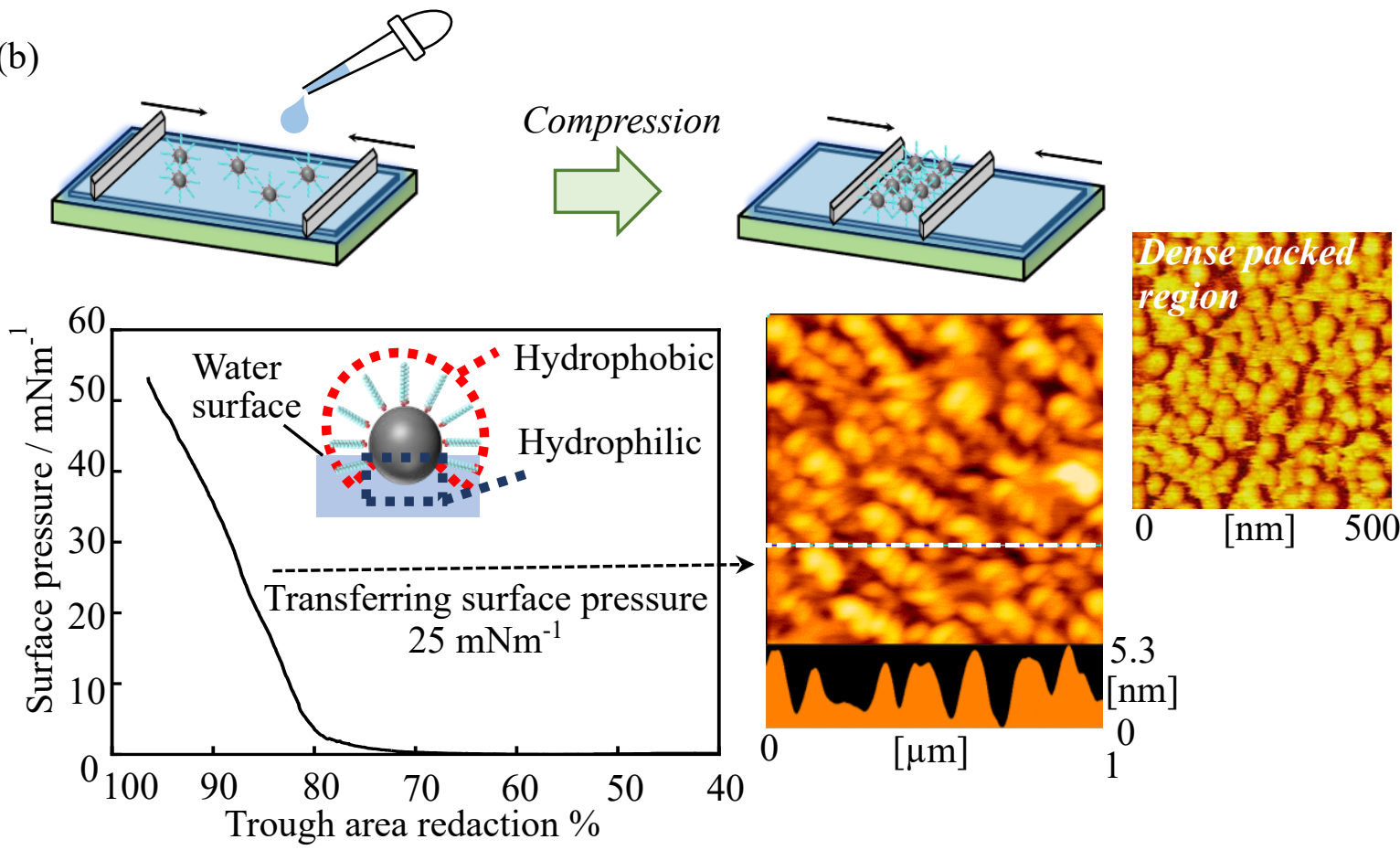

Figure S1

T. Ohashi, et al 
(a)

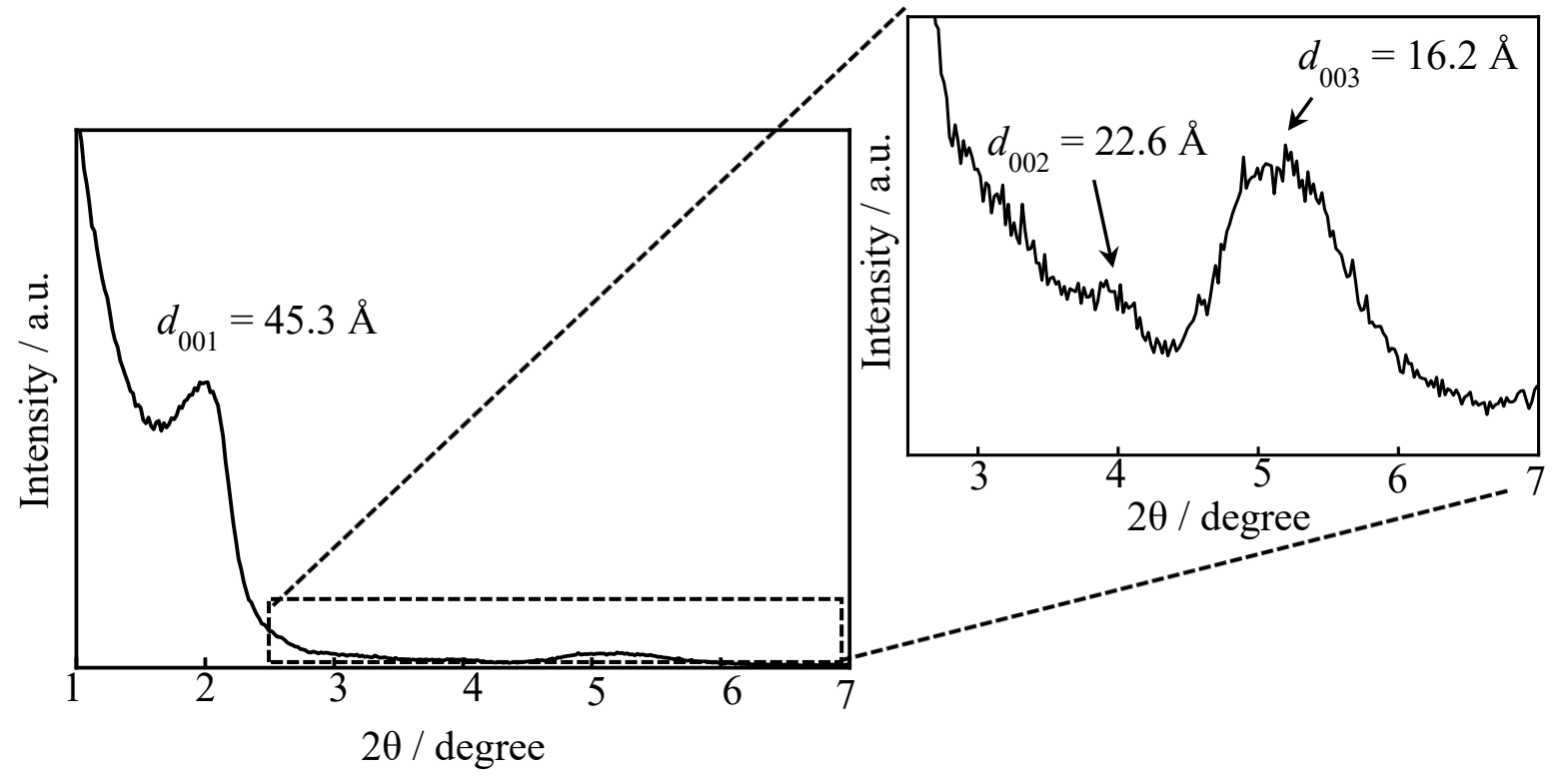

(b)

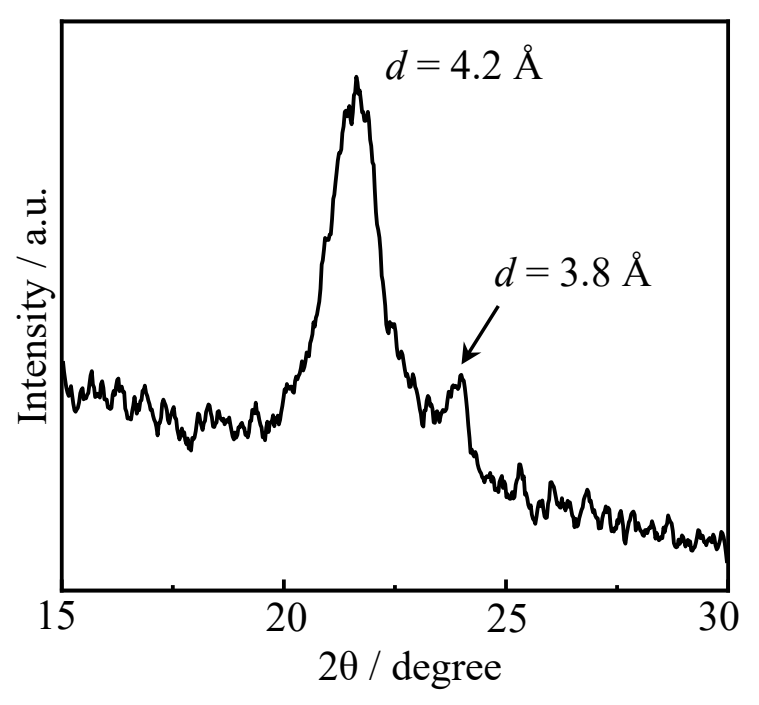

Figure S2 
(a)
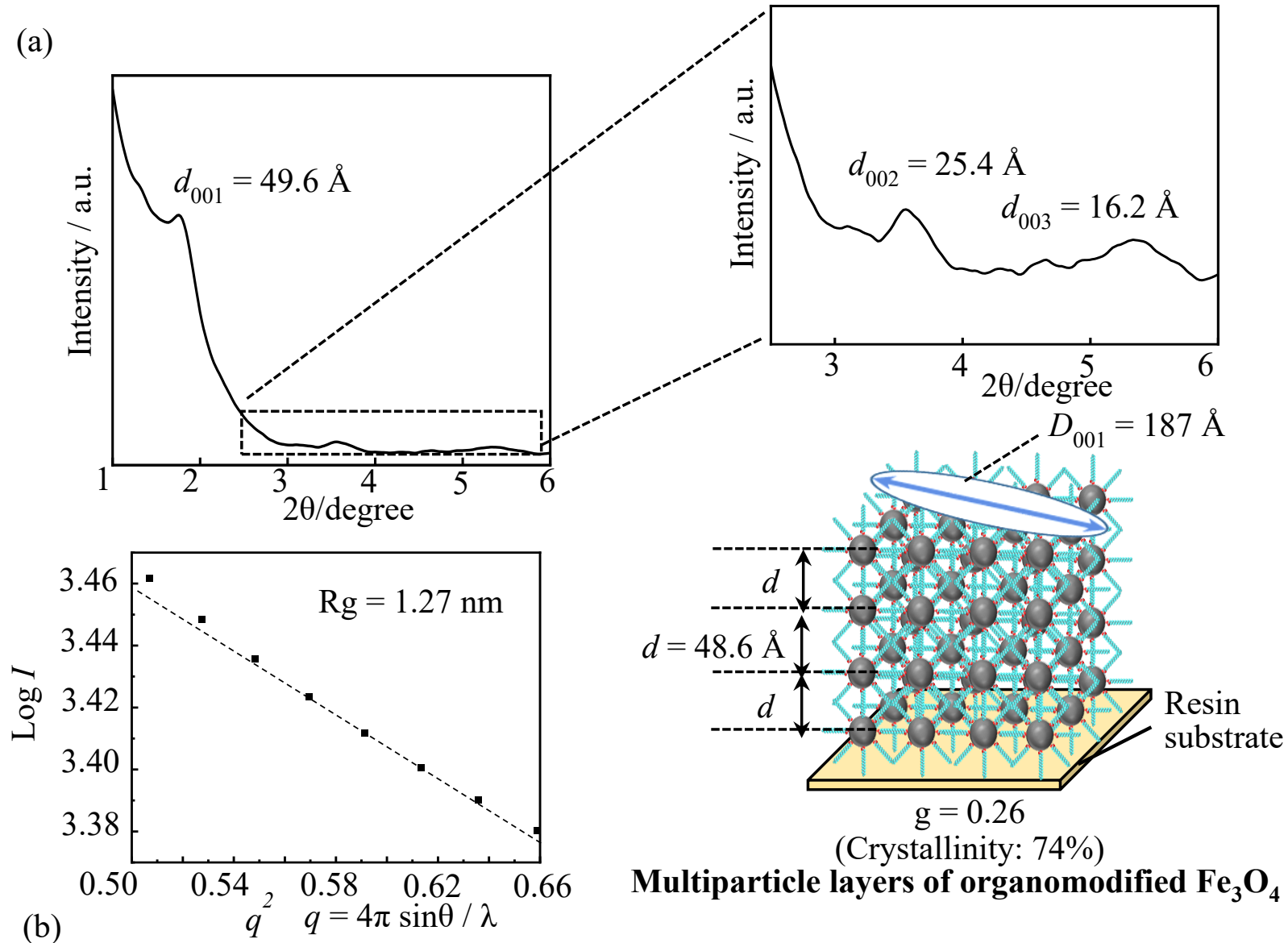

(Crystallinity: 74\%)

Multiparticle layers of organomodified $\mathrm{Fe}_{3} \mathrm{O}_{4}$
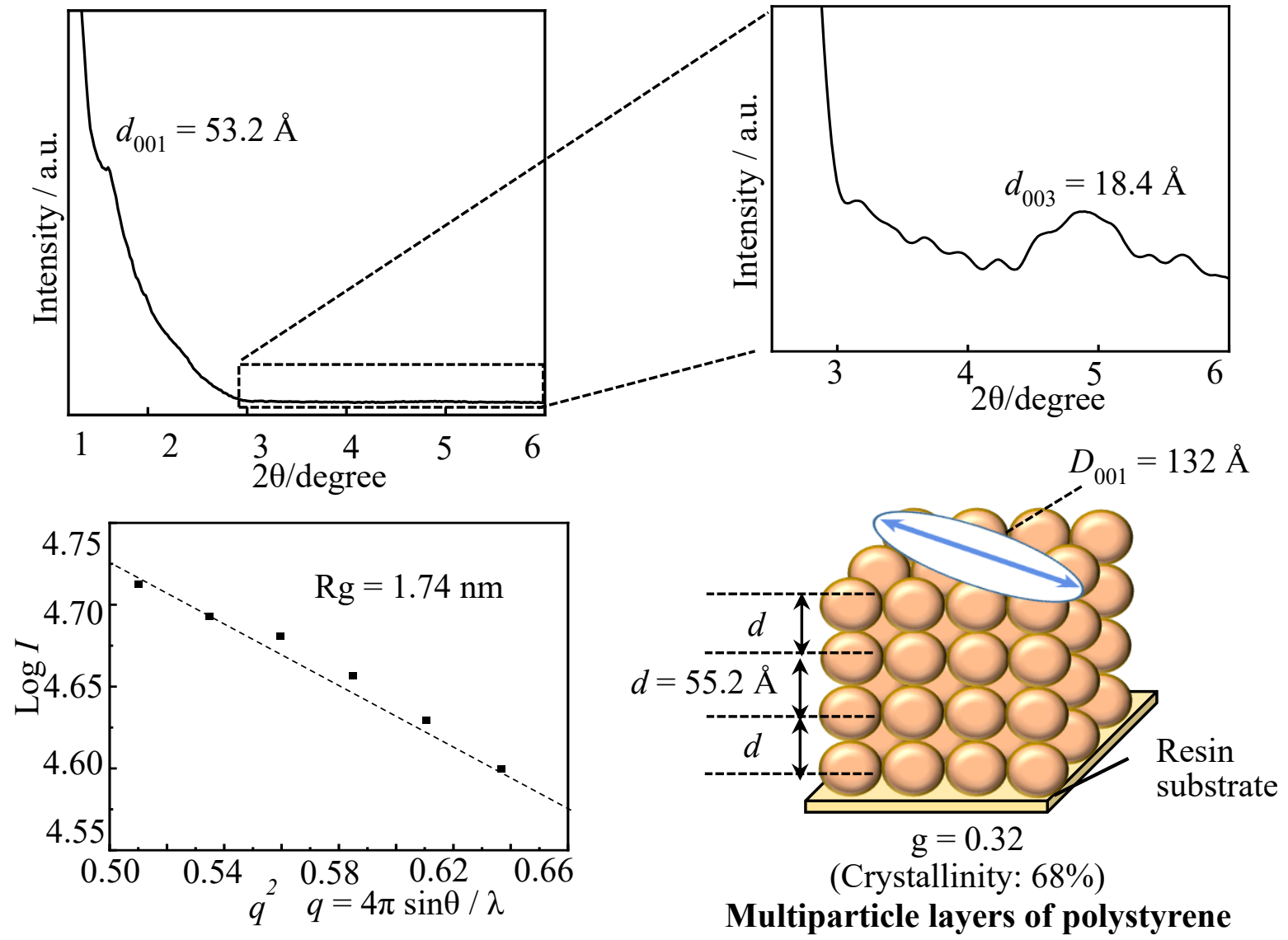

Figure S3

T. Ohashi, et al 

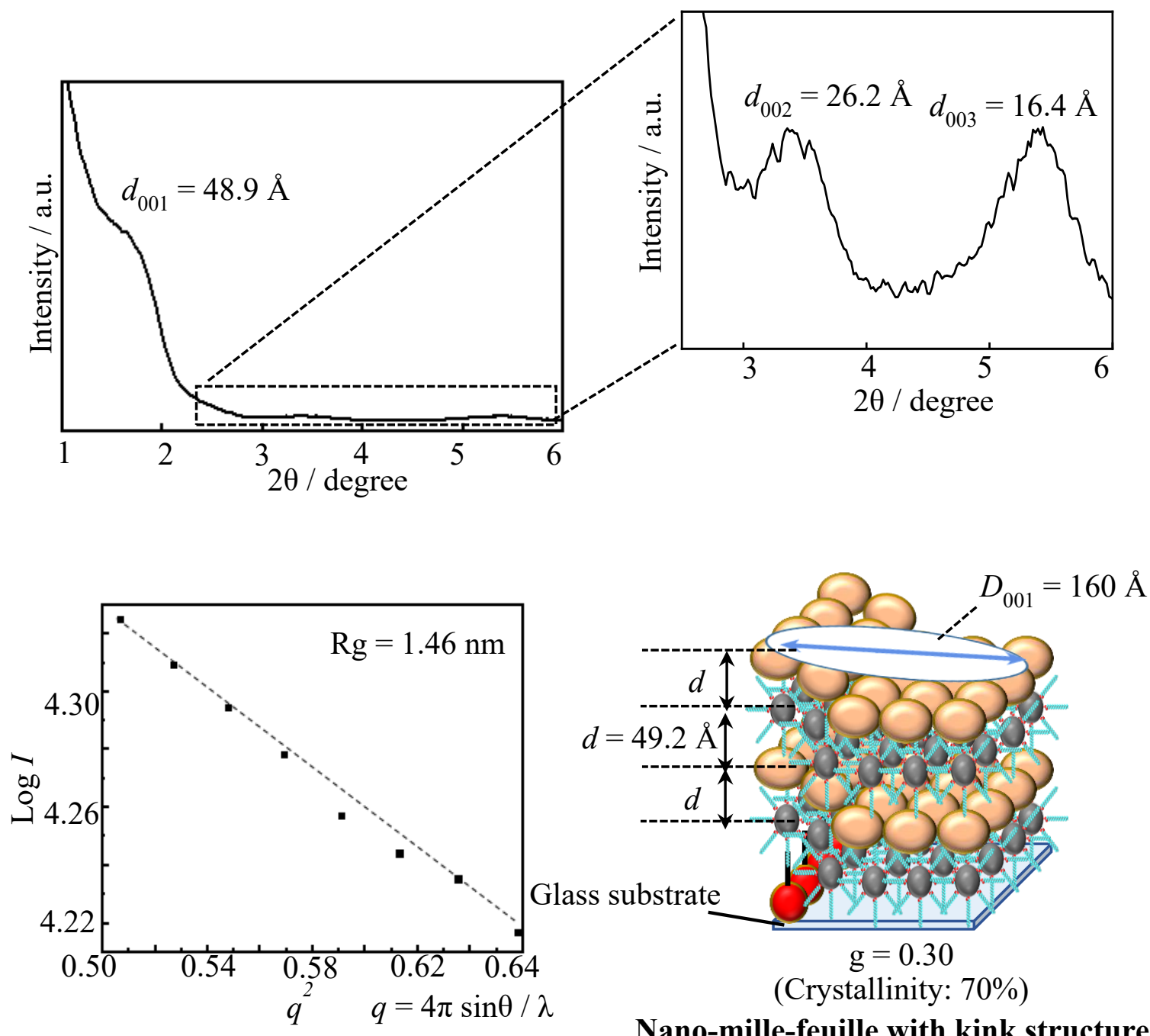

Nano-mille-feuille with kink structure 


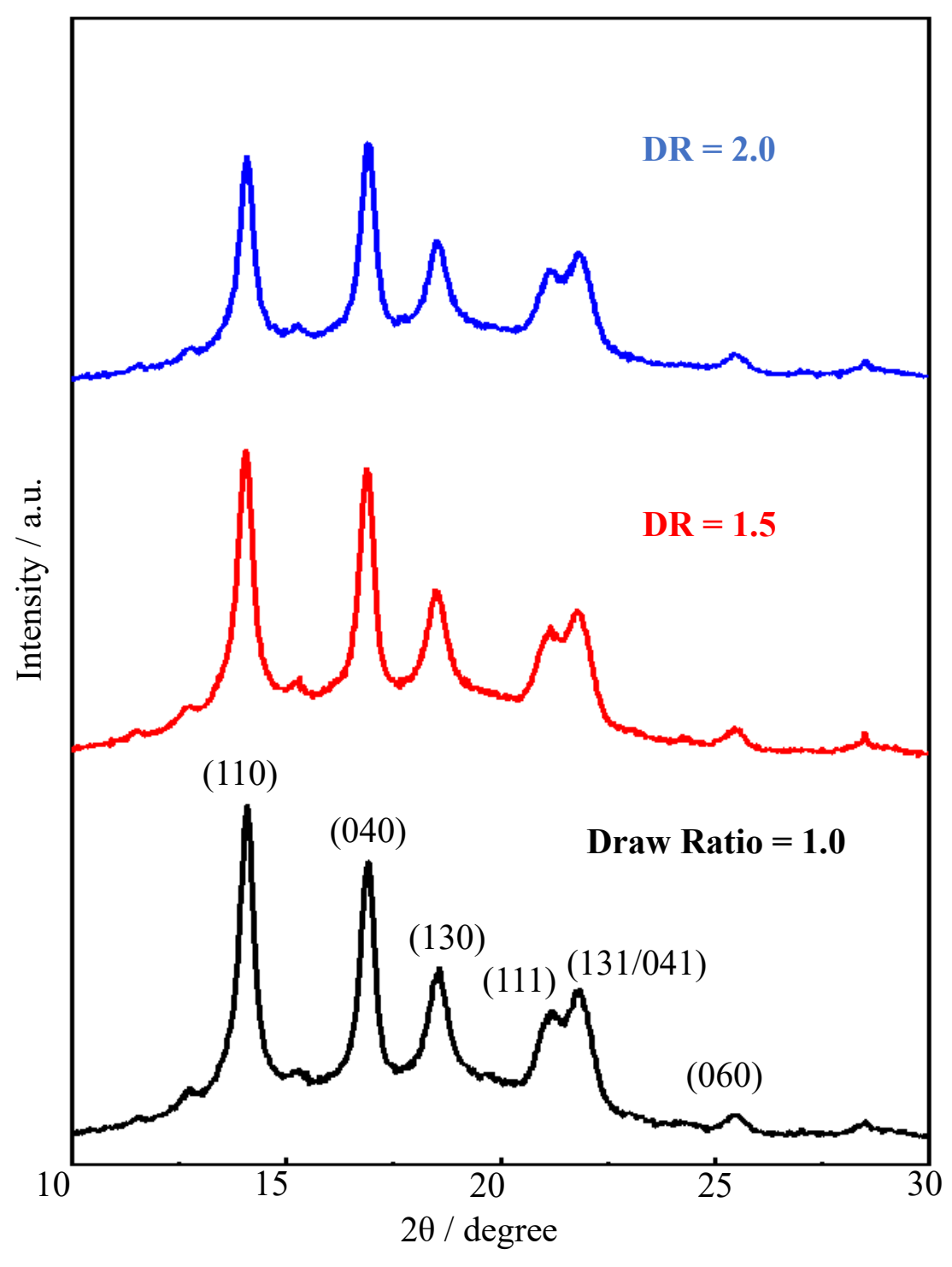

Drawing

Figure S5

T. Ohashi, et al 


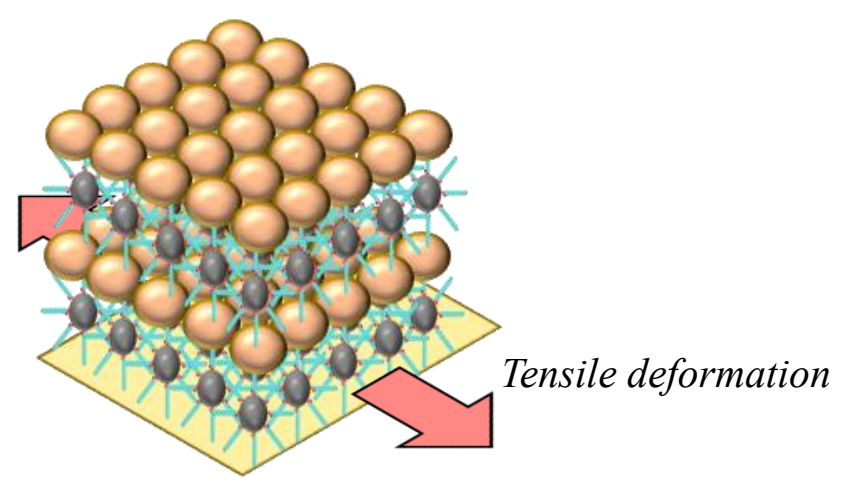

Nano-mille-feuille structure
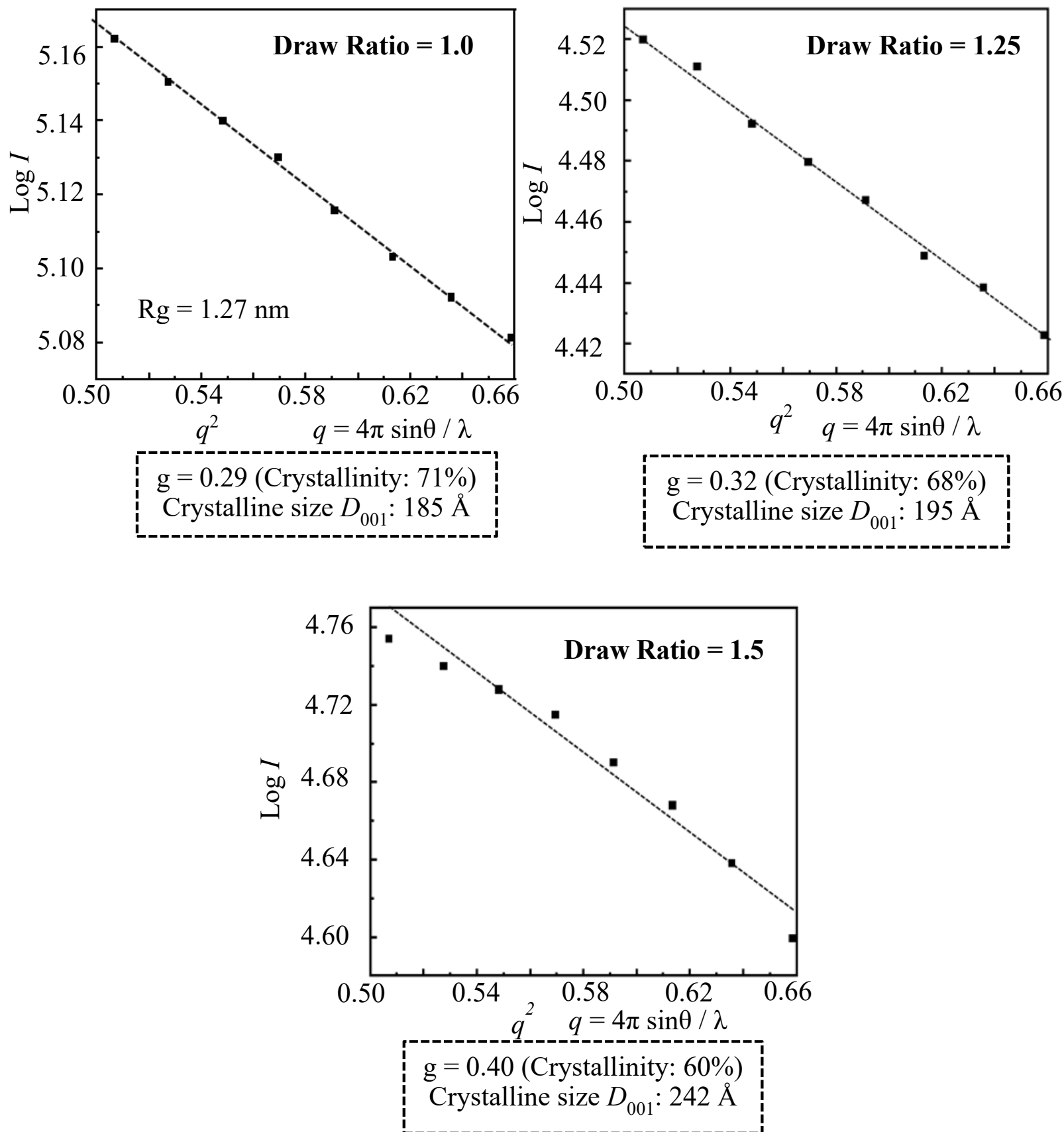

Figure S6

T. Ohashi, et al 


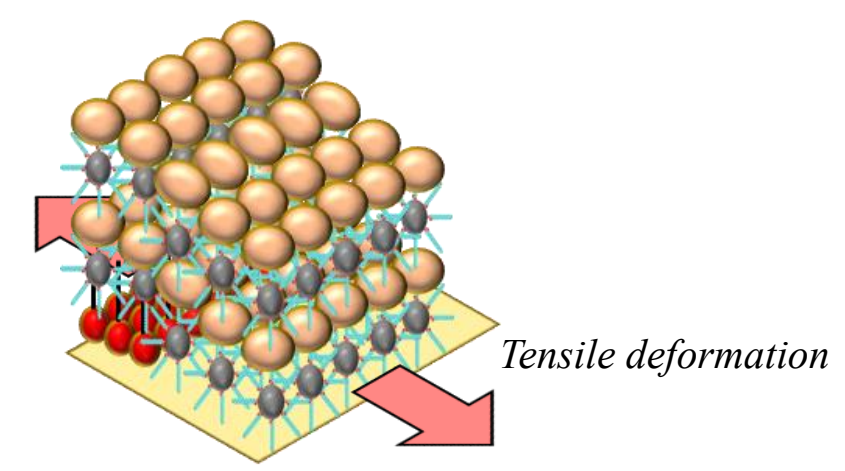

Nano-mille-feuille structure with kink structure
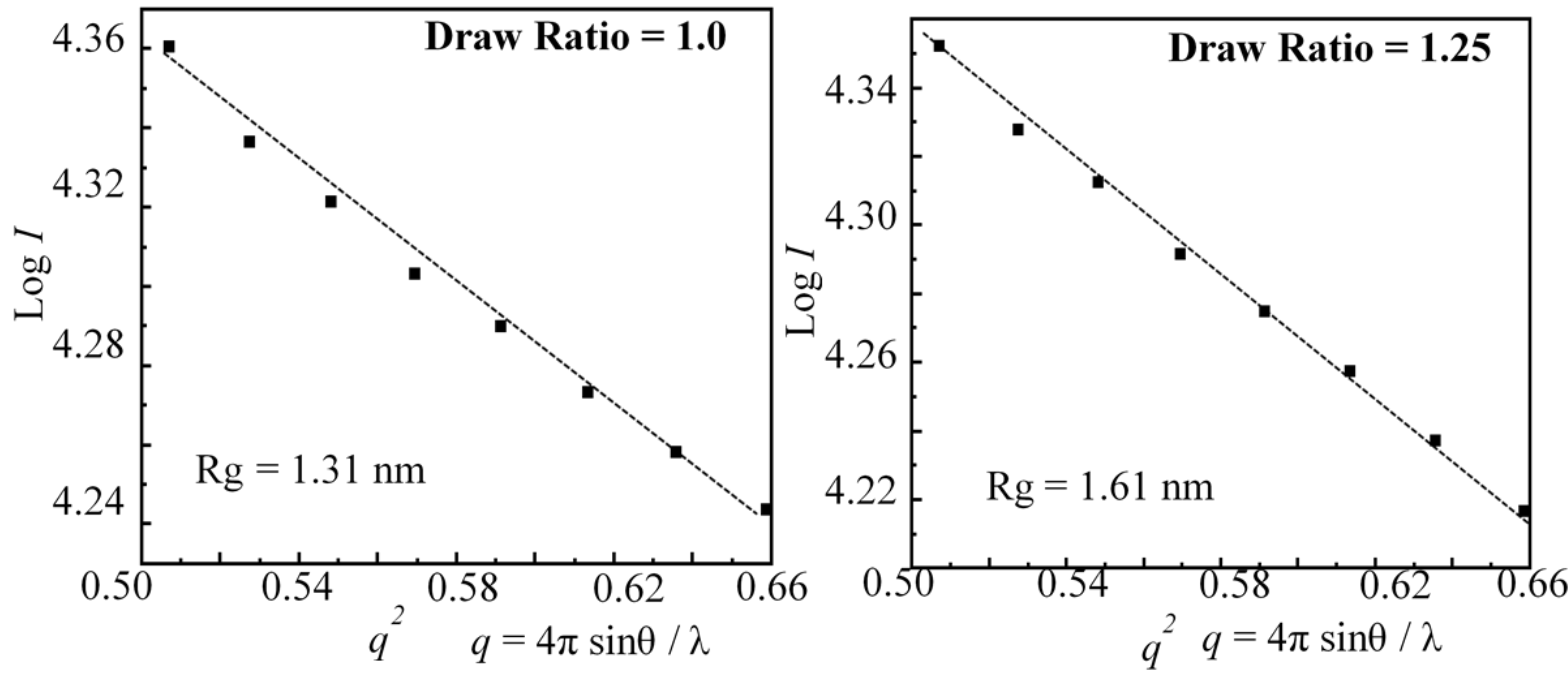

Crystallinity: $71 \%$

Crystalline size: $203 \AA$

Crystallinity: $68 \%$

Crystalline size: $203 \AA$

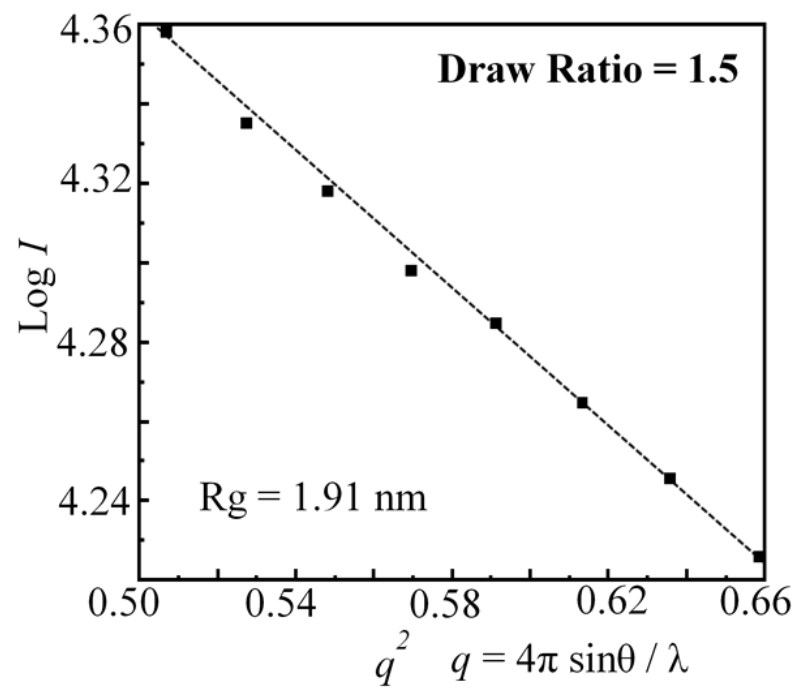

Crystallinity: $65 \%$

Crystalline size: $204 \AA$ 
* This figure cannot be displayed as a PDF file, so it is provided as a separate file. 


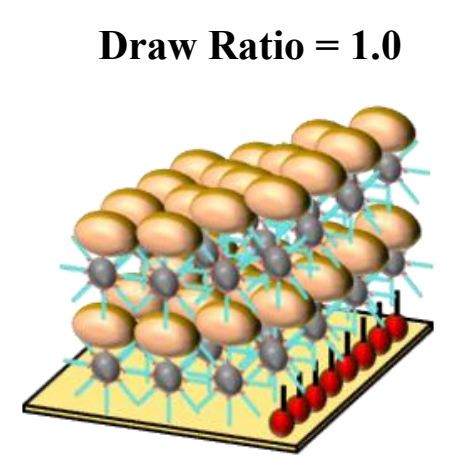

Nano-mille-feuille structure with kink structure

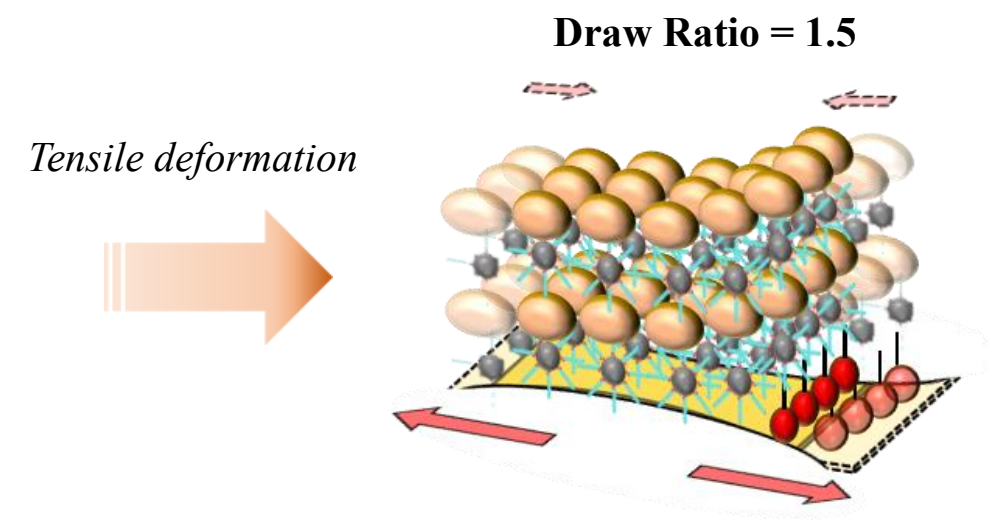

Repeating tensile deformation at $\mathrm{DR}=1.5$

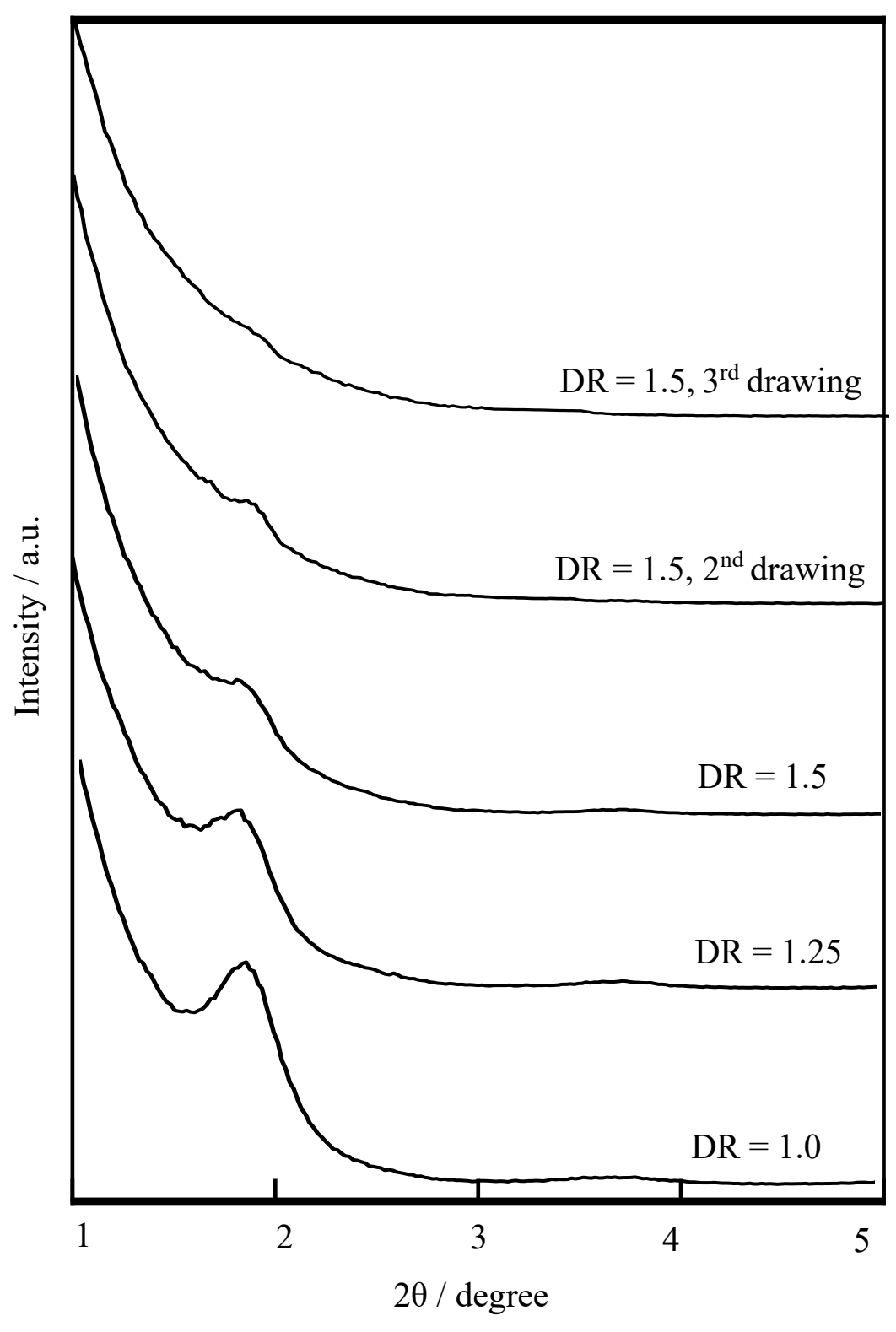

Figure S9 